\title{
Differential Gender Performance on the Major Field Test-Business
}

\section{Authors: Agnieszka Bielinska-Kwapisz and F. William Brown}

This is an Accepted Manuscript of an article published in Journal of Education for Business January 2013, available online: http://www.tandfonline.com/10.1080/08832323.2012.666296.

Bielinska-Kwapisz, Agnieszka, and F. William Brown. "Differential Gender Performance on the Major Field Test-Business." Journal of Education for Business 88, no. 3 (January 2013): 159166. doi: 10.1080/08832323.2012.666296.

Made available through Montana State University's $\underline{\text { ScholarWorks }}$ scholarworks. montana.edu 


\title{
Differential Gender Performance on the Major Field Test-Business
}

\author{
Agnieszka Bielinska-Kwapisz and F. William Brown \\ Montana State University, Bozeman, Montana, USA
}

\begin{abstract}
The Major Field Test in Business (MFT-B), a standardized assessment test of business knowledge among undergraduate business seniors, is widely used to measure student achievement. Many previous studies analyzing scores on the MFT-B report gender differences on the exam even after controlling for student's aptitude, general intellectual ability, and motivation. The authors' results point to two reasons behind this phenomenon. First, it is important to control for critical thinking abilities while explaining variation in MFT-B scores. Second, motivation to perform well on the test varies between genders and high- and low-performing students.
\end{abstract}

Keywords: assessment of learning, critical thinking, gender differences, MFT-B, quantile regression

The Major Field Achievement Test in Business (MFT-B) is a widely used assessment of learning instrument intended for use with graduating seniors in postsecondary undergraduate business programs. The primary motivations for administering the test are typically related to general assessment of learning and curriculum development efforts and to offer external accrediting bodies, such as the Association to Advance Collegiate Schools of Business (AACSB), evidence that a program is fulfilling or making progress toward its stated mission. Martell (2007) reported that in 2006, $46 \%$ of business schools used the MFT-B instrument in their assessment of students' learning. The Educational Testing Service (ETS), the publisher of the instrument, reported that 132,647 individuals at 618 different institutions completed the MFT-B between 2005 and 2009 (Educational Testing Service, 2009). The ETS describes the instrument as designed to measure a student's knowledge and ability to apply significant facts, concepts, theories, and analytical methods related to business. The questions represent a wide range of difficulty, and the assessment attempts to cover both depth and breadth in assessing students' levels of achievement (Educational Testing Service, 2010). The test contains 120 multiple-choice items covering a common body of knowledge typical of undergraduate business education: accounting (15\%), management

Correspondence should be addressed to Agnieszka Bielinska-Kwapisz, Montana State University, College of Business, Bozeman, MT 59717, USA. E-mail: akwapisz@montana.edu
(15\%), economics (13\%), finance (13\%), marketing (13\%), quantitative business analysis (11\%), information systems (10\%), legal and social environment (10\%), and international issues (about $12 \%$ drawn from other content areas; Educational Testing Service, 2010). The scores range from 120 to 200 and the ETS reports the mean score to be 153.5 with a standard deviation of 13.7 for 2010-2011 (Educational Testing Service, 2011).

The MFT-B has attracted the attention of researchers seeking to identify the determinants of student performance on this widely used assessment. Standardized test scores (ACT/SAT), grade point average (GPA), majors field of study, and gender have been consistently cited as determinative covariates (Bielinska-Kwapisz, Brown, \& Semenik, 2012a, 2012b; Black \& Duhon, 2003; Bycio \& Allen, 2007). This study extends the research stream by further and specifically examining the size and heretofore, unexamined nature of reported MFT-B performance differentials attributed to gender.

Gender, specifically male advantage, has been reported in several studies of performance on the MFT-B. BielinskaKwapisz et al. (2012a) reported that men perform better than women by 4.33 points after controlling for ACT scores, GPA, and an offer of extra credit for performance. Mason, Coleman, Steagall, Gallo, and Fabritius (2011) reported a 4.9point male advantage on the MFT-B while controlling for GPA, SAT, age, transfer, race, and major; while Bagamery, Lasik, and Nixon (2005) reported male scores on the MFT-B that were eight points higher than those from women when controlling for essentially the same stock of covariates. Black 
and Duhon (2003) reported a 3.79-point male advantage, while Bean and Bernardi (2002) report a 3.64-point male advantage. Contreras, Badua, Chen, and Adrian (2011) and Mirchandani, Lynch, and Hamilton (2001) also found that men significantly outperformed women while controlling for standard covariants and dispositional factors.

Terry, Mills, Rosa, and Sollosy (2009), in a study of the MFT-B performance of online students, did not find gender to be a significant predictor of MFT-B scores when they controlled for ACT scores, GPA, transfer, internationalism, and participation in online business education; however, in their study group, students' percentage score on the MFT-B assessment accounted for either $10 \%$ or $20 \%$ of the course grade in a business capstone course. They reported that a $10 \%$ contribution of MFT-B performance to the capstone course grade resulted in a $12.91 \%$ increase in the MFT-B percentile score and a $20 \%$ contribution to course grade resulted in an $18.1 \%$ score increase. These results were consistent with results reported by Bycio and Allen (2007) who, using a self-reported motivation scale, had previously reported that student motivation is an important determinant of performance on the MFT-B.

While the overwhelming majority of studies of performance on the MFT-B report gender differences and male overperformance, the nature and determinants of those differences have neither been explained or speculated on. This study's objective is to attempt to fill this gap in the understanding of the determinants of MFT-B scores. The possibility of a male advantage in the MFT-B raises the specter of a threat to the validity of this widely used measure of academic achievement among undergraduate business students, an issue that needs to be fully examined and understood.

This study seeks to contribute an understanding of these observed differences in gender performance in two ways. First, a measure of critical thinking ability will be introduced into the explanatory scheme in an effort to more completely examine the impact of gender differences on MFT-B performance. The other main approach in the study, informed by results reported by Terry et al. (2009) and Bycio and Allen (2007), is to examine the impact of motivation on performance and the possibility of differential gender reactivity to an offer of extra or course credit incentives linked to MFT-B performance.

The study begins with a description of the setting and data used to consider these heretofore unexamined relationships. Distributions of MFT-B scores, ACT scores, GPA, and measures of critical thinking ability by gender are described along with an examination of the determinants and intercorrelations of the MFT-B. Analysis of gender differences in MFT-B scores when extra credit is offered is provided, along with an examination of gender performance on the MFT-B across different academic majors. Quantile regression was used to examine differences in genders along the distribution of the MFT-B scores.

\section{DATA AND METHOD}

The setting for the present study was an undergraduate college of business at a Carnegie Research I, Land Grant University, which has held continuous AACSB accreditation for over 25 years. Students at the focal institution are predominantly Caucasian with a small population of international and ethnic students. As an element of a comprehensive assessment of learning process, the MFT-B has been administered to every graduating senior at this institution from the summer semester of 2005 through the spring of 2009. Background data utilized in the study were obtained from student records. The total number of students in the study population was 885. Full data, most notably MFT-B and ACT scores, were available for 692 students, with the difference primarily attributable to the fact that transfer students were not required to submit ACT scores. In addition, for each of the 692 students in the core study, the data include university GPA measured at graduation, gender, and major area of study (accounting, finance, management, or marketing). Beginning in the spring semester of 2008, students received extra credit points in their capstone business course to incent their best efforts on the MFT-B (5 points for a 50th percentile score, 7.5 points for 75 th percentile, and so on).

Critical thinking skills are generally defined as the ability to evaluate sources of information, challenge assumptions, understand context, analyze arguments, and use metacognition (Brookfield, 1987; King \& Kitchener, 1994; Kurfiss, 1988). In this study critical thinking was measured with the California Critical Thinking Skills Test (CCTST; Facione \& Facione, 1994).

Published by the California Academic Press, the CCTST is a multiple-choice educational assessment tool specifically designed to assess selected core critical thinking skills (Facione, 1990). The CCTST is widely used throughout the United States and internationally (Insight Assessment, 2011). The test consists of 34 multiple-choice items yielding an overall measure of critical thinking skills and five sub-scales measuring: analysis, evaluation, inference, deductive reasoning, and inductive reasoning (Jacobs, 1995). The CCTST has been demonstrated to have acceptable reliability and validity when used to assess critical thinking skills in college students (Facione \& Facione, 1994; Facione, Giancarlo, Facione, \& Gainen, 1995). As a part of the institutional assessment of learning agenda, the CCTST was administered to every graduating senior from the spring semester 2006 to spring 2007, a total of 327 students.

Table 1 reports the full list of variables, their definitions, and descriptive statistics. Additionally, there are no very high (above \pm .5 ) correlations between any pair of independent variables (table not reported). Therefore, we believe multicollinearity was of no consequence in the analyses. There are statistically significant observed differences between male and female MFT-B scores and GPA in the sample means. Interestingly, males outperformed females on the MFT-B 
TABLE 1

Definitions and Descriptive Statistics

\begin{tabular}{|c|c|c|c|c|c|c|}
\hline Variable & Description & $M$ & $S D$ & Minimum & Maximum & $n$ \\
\hline MFT-B & Student MFT-B score on a scale of $120-200$ & 161.49 & 12.28 & 128 & 194 & 885 \\
\hline ACT & Student ACT score on a scale of $1-36$ & 23.39 & 3.46 & 14 & 34 & 692 \\
\hline GPA & GPA measured at the time of graduation & 3.13 & 0.40 & 1.99 & 4 & 880 \\
\hline СTTOT & Total critical thinking score on a scale of 0-34 & 20.39 & 4.44 & 8 & 31 & 327 \\
\hline CTANAL & Analysis & 4.84 & 1.19 & 1 & 7 & 327 \\
\hline CTINF & Inference & 10.10 & 2.41 & 2 & 15 & 327 \\
\hline CTEVAL & Evaluation & 5.45 & 2.08 & 0 & 11 & 327 \\
\hline CTDED & Deductive & 9.24 & 2.76 & 2 & 16 & 327 \\
\hline CTIND & Inductive & 11.15 & 2.30 & 4 & 16 & 327 \\
\hline Male & Binary variable $=1$ if male & 0.54 & - & 0 & 1 & 885 \\
\hline ExCredit & Binary variable $=1$ if extra credit was offered & 0.41 & - & 0 & 1 & 885 \\
\hline FIN & Binary variable $=1$ if finance major & 0.17 & - & 0 & 1 & 885 \\
\hline ACCT & Binary variable $=1$ if accounting major & 0.22 & - & 0 & 1 & 885 \\
\hline MGMT & Binary variable $=1$ if management major & 0.33 & - & 0 & 1 & 885 \\
\hline MKTG & Binary variable $=1$ if marketing major & 0.27 & - & 0 & 1 & 885 \\
\hline
\end{tabular}

Note. MFT-B = Major Field Test in Business.

(male $M=162.7$ vs. female $M=160.0$ ), while women's GPAs were higher (male $M=3.05$ ] vs. female $M=3.22$ ). Study results suggest that female students had higher GPAs even after controlling for the variation in their ACT scores. Similar results were reported in other settings (e.g., Siebert et al., 2006; Stater, 2009) and were intuitively attributed to higher academic motivation among females. The Levene test for the equality of variances was performed and the only statistically significant differences observed were between male and female variances of MFT-B scores (female variance = 135.2 vs. male variance $=162.5$ ) and CCTST subscores for inductive reasoning (female variance $=4.63$ vs. male variance $=5.87$ ). Therefore, men had higher MFT-B mean scores but larger variance in those scores.

\section{RESULTS}

\section{Determinants of MFT-B scores}

A number of studies have examined the effect of student characteristics on performance on the MFT-B (Allen \& Bycio, 1997; Bagamery et al., 2005; Bean \& Bernardi, 2002; Bielinska-Kwapisz \& Brown, 2011; Bielinska-Kwapisz et al., 2012a, 2012b; Black \& Duhon, 2003; Bycio \& Allen, 2007; Contreras et al., 2011; Mason et al., 2011; Mirchandani et al., 2001; Stoloff \& Feeney, 2002; Terry et al., 2009; Zeis, Waronska, \& Fuller, 2009.) Most of those studies included standardized test scores (ACT/SAT), GPA, majors, and gender as independent variables. However, none of the previous literature analyzing MFT-B scores controlled for students' critical thinking abilities and only a few studies analyzed the effect of critical thinking on the performance on class exams. Jenkins's (1998) results suggest that students with higher measures of critical thinking skills (as measured by the Watson Glaser Critical Thinking Appraisal test) and past academic performance outperformed other students on a class exam and a comprehensive final examination in an upper-division auditing course. In the same study, gender and age proved insignificant across all auditing examination scores, while GPA was significantly predictive of performance on two previous course exams. Roberts and Dyer (2005) used the Engagement, Maturity, and Innovativeness Critical Thinking Disposition Inventory test and showed that motivation, self-efficacy, and critical thinking disposition explained $8.8 \%$ of the variance in a linear combination of attitudes and post-test achievement.

\section{Gender, Critical Thinking, and the MFT-B}

To examine the effect of gender and critical thinking on the variation in MFT-B scores, the following basic model was utilized:

$$
\begin{aligned}
\text { MFT }-B_{i k}= & \beta_{0}+\beta_{1} A C T_{i k}+\beta_{2} G P A_{i k}+\beta_{3} \text { Male }_{i k} \\
& +\beta_{4} \text { ExCredit }_{i k}+\beta_{5} C T_{i k}+\eta_{k}+\varepsilon_{i k},
\end{aligned}
$$

where $M F T-B_{i k}$ is the MFT-B score of student $i$ in major $k$; $A C T_{i k}$ is ACT score; $G P A_{i k}$ is overall GPA; Male $_{i k}$ is a binary variable that takes the value of 1 if a student is a man and 0 if a woman; ExCredit ${ }_{i k}$ is a binary variable that takes the value of 1 if a student could receive extra points for a good performance; $C T_{i k}$ is the CCTST score or a subscales score; $\eta_{k}$ are majors' fixed effects; $\beta$ s are coefficients to be determined; and $\varepsilon_{i k}$ is the error term. In the context of this study, ACT scores were used as a proxy for general cognitive capability (Koenig, Frey, \& Detterman, 2008) and GPA as a measure of time input and effort. Several variations of the previous model were estimated and the results from the best regressions are presented in Table 2. During the period in which the CCTST test scores were obtained, extra credit for MFT-B 
TABLE 2

Regression Results (Dependent Variable of MFT-B Score)

\begin{tabular}{|c|c|c|c|c|c|c|}
\hline \multirow[b]{2}{*}{ Variable } & \multicolumn{2}{|c|}{ Model 1: All data $(n=692)$} & \multicolumn{2}{|c|}{$\begin{array}{l}\text { Model 2: Data limited to } \\
\text { CCTST }(n=238)\end{array}$} & \multicolumn{2}{|c|}{$\begin{array}{l}\text { Model 3: Controlling for } \\
\text { CCTST inference }(n=238)\end{array}$} \\
\hline & Coefficient & $t$ & Coefficient & $t$ & Coefficient & $t$ \\
\hline Constant & 99.32 & 30.2 & 99.05 & 19.28 & 100.11 & 20.22 \\
\hline ACT & 1.50 & 13.5 & 1.47 & 8.43 & 1.01 & 5.08 \\
\hline GPA & 8.50 & 8.5 & 9.10 & 5.62 & 8.44 & 5.39 \\
\hline Male & 4.33 & 6.2 & 2.77 & 2.44 & 1.86 & 1.68 \\
\hline Finance & 1.67 & 1.5 & 2.43 & 1.28 & 2.82 & 1.54 \\
\hline Management & -3.63 & 3.8 & -3.29 & 1.99 & -3.18 & 2.00 \\
\hline Marketing & -5.82 & 5.9 & -5.37 & 3.12 & -5.30 & 3.20 \\
\hline ExCredit & 1.29 & 1.9 & - & & - & \\
\hline CCTST inference & - & & - & & 1.21 & 4.40 \\
\hline
\end{tabular}

Note. For Model $1, R^{2}=.5013$, adjusted $R^{2}=.4962$. For Model $2, R^{2}=.5119$, adjusted $R^{2}=.4992$. For Model $3, R^{2}=.5500$, adjusted $R^{2}=.5360$. For dependent variable FEMALE MFT, $R^{2}=.480$, adjusted $R^{2}=.4698$. CCTST $=$ California Critical Thinking Skills Test; GPA = grade point average; MFT-B $=$ Major Field Test in Business.

performance was not offered to students. Therefore, Model 1 $(n=692)$ in Table 2 uses all data, but the rest of the models employ only data collected during the time period when the CCTST test was administered $(n=238)$. Our results suggest that the best explanatory model includes the inference subscale of the CCTST (Model 3) and explains about 54\% of variation in the MFT-B scores. This model suggests that the GPA was the most important predictor of MFT-B scores. A $10 \%$ increase in GPA increases MFT-B by $1.6 \%$ (all elasticities were calculated at sample means). The impact of ACT was similar: a 10\% increase in ACT scores increased MFT$\mathrm{B}$ by $1.46 \%$. The impact of the critical thinking score was smaller: A $10 \%$ increase in the critical thinking inference score increased the MFT-B by $0.1 \%$. Consistent with reports from previous studies management and marketing students achieved lower scores on the MFT-B exam as compared to accounting students (Barboza \& Pesek, 2012; Black \& Duhon, 2003; Mason et al., 2011).

Of particular interest in this study is the coefficient of the male variable. In Model 3, after controlling for the critical thinking inference scores, the coefficient of the male variable was insignificant. Therefore, critical thinking inference scores may explain the difference between male and female scores on the MFT-B. Compared to Model 2, which used the same sample of observations, but did not control for critical thinking, the coefficient was smaller by $33 \%$ and insignificant. These results suggest that differences in critical thinking inference scores may be responsible for the difference between male and female scores on the MFT-B reported in previous studies.

\section{Gender, Extra Credit, and the MFT-B}

To further analyze gender differences on MFT-B scores, the impact of an offer of extra credit contingent on performance was examined. GPA is frequently used as a measure of stu- dent's effort and, as previously noted, in the study sample women had overall significantly higher GPA scores than men. Therefore, we hypothesized that the extra credit offered for good performance on the MFT-B exam would impact women's scores less than men's scores because female students may already be performing at peak levels and would not need or be benefited by an incentive to increase effort. Therefore, the estimation was performed separately by gender and the results are presented in Table 3. Most of the male and female coefficients were quite similar to one another. As before, the most important variables in explaining the variation of the MFT-B scores were ACT and GPA; however, quite interestingly there were significant differences between male and female students' response to the extra credit offer: Males who were offered extra credit for performance on the MFT-B had, on average, MFT-B scores 2.48 points higher than male scores received in years that extra credit was not offered. However, the extra credit coefficient for women was

TABLE 3

MFT-B by Gender $(n=692)$

\begin{tabular}{lcrlrr}
\hline & \multicolumn{2}{c}{$\begin{array}{c}\text { Dependent variable: } \\
\text { MALE MFT }\end{array}$} & & \multicolumn{2}{c}{$\begin{array}{c}\text { Dependent variable: } \\
\text { FEMALE MFT }\end{array}$} \\
\cline { 2 - 3 } \cline { 6 - 6 } & Coefficient & $t$ & & Coefficient & $t$ \\
\hline Intercept & 100.35 & 21.93 & & 103.73 & 22.94 \\
ACT & 1.56 & 10.23 & & 1.44 & 8.94 \\
GPA & 9.13 & 6.49 & & 7.62 & 5.40 \\
Extra Credit & 2.48 & 2.61 & & -0.29 & -0.31 \\
FIN & 0.90 & 0.59 & & 1.93 & 1.14 \\
MGMT & -4.45 & -3.11 & & -2.69 & -2.08 \\
MKTG & -6.60 & -4.24 & & -5.32 & -4.29 \\
\hline
\end{tabular}

Note. For dependent variable MALE MFT, $R^{2}=.5080$, adjusted $R^{2}=$ .5000 . For dependent variable FEMALE MFT, $R^{2}=.4800$, adjusted $R^{2}=$ .4698. MFT-B $=$ Major Field Test in Business; GPA = grade point average. 
not significant and actually had a sign in an unanticipated direction.

To further analyze the reaction of students to an extra credit offer, the differences throughout the MFT-B distribution were examined using quantile regression. Quantile regression was initially described by Koenker and Bassett (1978) and Koenker and Hallock (2001) and is based on the minimization of weighted absolute deviations for estimating conditional quantile functions. Quantile regression models the relation between a set of independent variables and specific percentiles (or quantiles) of the dependent variable. Unlike linear regression, in which the regression coefficient represents the change in the dependent variable produced by a one-unit change in the associated independent variable, quantile regression parameters estimate the change in a specified quantile of the dependent variable produced by a one unit change in the independent variable. Quantile regression makes use of the entire sample and is not equivalent to utilizing the dependent variable series of subsamples and applying ordinary least squares (OLS) to those subsamples. Therefore, quantile regression is not the same as dividing the data into percentiles and then applying OLS to those percentiles (e.g., Hallock, Madalozzo, \& Reck, 2008). Quantile regression has been used in educational settings by Eide and Showalter (1998); Escudero, Giovagnoli, and Porto (2009); Levin (2001); Prieto-Rodriguez, Barros, and Vieira (2008); and Robinson and Lubienski (2011). Bielinska-Kwapisz and Brown (2011) employed quantile regression to estimate whether the performance returns on certain student characteristics in business programs differ along the conditional distribution of their MFT-B test scores.

In Table 4, estimated coefficients at the 5th, 25th, 50th, 75th, and 95th percentiles of the overall MFT-B male score distribution quantiles are reported. By comparison, OLS coefficients for male scores reported in Table 3 are repeated in the first column. The results suggest that ACT and GPA scores were significant determinants of male MFT-B scores along the whole distribution. However, the effect of the extra credit was not uniform throughout the male MFT-B scores distribution. Recalling that, on average, extra credit offers increased overall male scores by 2.48 points it is interesting to note that the effect was not the same for all quartiles. There was almost no effect for the lowest fifth percentile $(0.56 ; p=$ $.75)$ and the effect remained insignificant at 25 th percentile $(1.49 ; p=.29)$. The extra credit effect became significant at the median $(2.35 ; p=.025)$ and increased to 2.92 at 75 th percentile $(p=.04)$. The effect peaked at 3.62 for the top fifth percentile of male MFT-B scores $(p=.006)$. Similar quantile regression was performed for women. In that instance an extra credit offer was not significant and had an unexpected negative sign for the OLS and for all quantiles except at the 95\% quantile when the sign became positive, although remaining statistically insignificant $(2.38 ; p=.15)$. Therefore, the extra credit incentive was not significant for any females in the study and up to the median for the male distribution. However the extra credit incentive had a significant positive impact on the top 50th percentile of men.

\section{Analysis by Major}

Significant differences in MFT-B scores by major (Table 2) were observed in this study. As previously noted, similar differences were reported in previous studies with marketing and management student performance on the MFT-B inferior to finance and accounting student performance while controlling for standard variables (ACT, GPA, gender). However, the previous literature is silent in regard to the impact of gender differences by major. Table 5 presents the results of the OLS and quantile regressions where the MFT-B scores are the dependent variable and ACT, GPA, extra credit, and male are the independent variables. In this instance regressions were performed by major and only coefficients on the male variable are reported. The results from the OLS regression show that for all majors, men outperform women on the MFT-B with score differentials ranging from 3.53 points in marketing to 6.38 in accounting. However, the results from the quantile regression show large differences across majors and quantiles. Overall, the largest observed differences between males and females were in accounting (all accounting quantile coefficients were above all quantiles from

TABLE 4

MFT-B Males by Quartile

\begin{tabular}{|c|c|c|c|c|c|c|c|c|c|c|c|c|}
\hline & \multicolumn{2}{|c|}{ OLS Table 3 (Males) } & \multicolumn{2}{|c|}{5 th } & \multicolumn{2}{|c|}{25 th } & \multicolumn{2}{|c|}{50 th } & \multicolumn{2}{|c|}{75 th } & \multicolumn{2}{|c|}{95 th } \\
\hline & Coefficient & $t$ & Coefficient & $t$ & Coefficient & $t$ & Coefficient & $t$ & Coefficient & $t$ & Coefficient & $t$ \\
\hline Intercept & 100.35 & 21.93 & 77.95 & 8.52 & 92.38 & 12.76 & 98.42 & 21.35 & 114.39 & 16.99 & 125.47 & 30.05 \\
\hline $\mathrm{ACT}$ & 1.56 & 10.23 & 1.56 & 6.85 & 1.62 & 7.04 & 1.66 & 10.39 & 1.39 & 6.08 & 1.29 & 6.08 \\
\hline GPA & 9.13 & 6.49 & 11.63 & 4.62 & 9.21 & 4.22 & 9.24 & 6.50 & 8.12 & 3.84 & 7.06 & 6.88 \\
\hline ExCredit & 2.48 & 2.61 & 0.56 & 0.32 & 1.49 & 1.05 & 2.35 & 2.25 & 2.92 & 2.01 & 3.62 & 2.78 \\
\hline FIN & 0.90 & 0.59 & -0.70 & -0.21 & 1.76 & 0.63 & 1.00 & 0.63 & 1.45 & 0.63 & 2.58 & 2.81 \\
\hline MGMT & -4.45 & -3.11 & -2.35 & -0.84 & -4.46 & -1.81 & -5.51 & -4.13 & -6.21 & -2.92 & -2.65 & -1.58 \\
\hline MKTG & -6.60 & -4.24 & -5.67 & -2.04 & -5.28 & -2.17 & -7.51 & -5.24 & -8.62 & -3.11 & -3.00 & -1.99 \\
\hline
\end{tabular}

Note. Adjusted $R^{2}$ for ordinary least squares $(\mathrm{OLS})=.5000$. MFT-B $=$ Major Field Test in Business; GPA $=$ grade point average. 
TABLE 5

Coefficients on Male From MFT $=f(A C T$, GPA, ExCredit, Male) by Major

\begin{tabular}{|c|c|c|c|c|c|c|c|c|}
\hline & \multicolumn{2}{|c|}{ Ordinary least squares } & \multicolumn{2}{|c|}{20 th } & \multicolumn{2}{|c|}{50 th } & \multicolumn{2}{|c|}{80 th } \\
\hline & Coefficient & $t$ & Coefficient & $t$ & Coefficient & $t$ & Coefficient & $t$ \\
\hline MGMT & 3.70 & 3.15 & 4.46 & 3.21 & 4.18 & 3.46 & 3.18 & 1.42 \\
\hline MKTG & 3.53 & 2.88 & 2.31 & 1.34 & 2.63 & 1.88 & 5.27 & 2.33 \\
\hline ACCT & 6.38 & 4.22 & 6.56 & 2.72 & 7.78 & 4.47 & 6.82 & 3.22 \\
\hline FIN & 4.37 & 2.13 & 2.24 & 0.56 & 5.18 & 2.93 & 8.59 & 1.98 \\
\hline
\end{tabular}

management and marketing and all but 80th percentile in finance). In finance, at the 80th percentile on MFT-B scores the male advantage was 8.59 points but was not significant at the lowest percentile. The same analysis was performed while controlling for critical thinking scores; however, as expected, none of the coefficients were significant.

\section{DISCUSSION AND CONCLUSIONS}

\section{Summary}

The MFT-B is intended to measure mastery of business knowledge by senior students in undergraduate business programs. It has been estimated that almost half of all colleges of business utilize the MFT-B as a part of their assessment of learning process and to support external accreditation by the AACSB. The MFT-B has attracted attention from researchers who have primarily focused on the determinants of performance on the assessment. Among other identified explanatory variables, previous studies have consistently reported a gender effect with male advantage. In the previous studies male MFT-B scores were significantly higher than female scores in a range from 3.6 to 8.4 points, even after controlling for general ability with ACT/SAT scores and effort with GPA. Using a large multiyear sample, we examined the nature of this gender effect and its implications for the use of MFT-B as an assessment instrument.

In the focal study sample $(n=692)$, men's MFT-B scores were 4.33 points higher than women's scores. These differences are statistically significant when controlling for ACT and GPA. The results of this study suggest that it is very likely that male advantage on the MFT-B emanates from two sources. First, and perhaps most importantly, is a genderbased difference in critical thinking skills. In this study, critical thinking was measured with the CCTST and even though no significant bivariate gender differences on the CCTST were observed, when control for ACT scores was introduced into the analysis, a significant male advantage appeared. A further examination of the impact of critical thinking on gender differences in MFT-B scores suggests that the inference subscale of the CCTST was the source of most of the explained differences. MFT-B gender differences by major were also analyzed. The largest gender differences were found in the top decile of finance majors, a difference, which is explained by the differential CCTST scores.

Additionally, our study results indicate that part of the gender differences on the MFT-B can also be explained by any performance incentives given to students to encourage best efforts when taking MFT-B. Significant gender differences in reactivity to those incentives were observed. In this study sample there was no female reactivity to an offer of extra course credit tied to performance on the MFT-B. But results do indicate that the top 50th percentile of males in the MFT-B distribution reacted positively and significantly to the same extra credit offer.

\section{Implications}

Results of our study are reassuring in regard to the possibility of gender bias in the MFT-B itself. However; as most of the difference between men and women on the MFT-B assessment can be explained by the differences in the critical thinking-inference abilities, it is important to include some measure of critical thinking while explaining or attempting to fully understand local variation in MFT-B scores. Our results also point to the criticality of critical thinking ability in academic performance.

The use of extra credit to incent best efforts when taking the MFT is also very interesting, but more complex. This study's results indicate that incentives tied to MFT-B performance will yield higher institutional scores, but almost all of that increase emanates from men in the top half of the MFT-B distribution. The argument in favor of an extra credit offer is that it may yield not just higher, but more accurate MFT-B scores, reflecting the full measure of business knowledge amongst the cohort completing the assessment. The argument against an extra credit offer is that extra credit may unfairly benefit men for doing something (making a best effort on the MFT-B) they should be doing anyway. However, women, apparently inclined to give their best effort absent an extra-credit offer, may be disadvantaged in a course or other setting where the extra credit is applied.

\section{Limitations}

The focal performance metric in this study was the MFTB. ETS, publishers of the MFT-B, described using subject matter experts to produce the assessment tools (Educational 
Testing Service, 2009), but provide no definitive evidence regarding validity - a factor that has attracted concerned attention (Allen \& Bycio, 1997; Parmenter, 2007). The value of the performance findings, albeit not necessarily the potential value of the methodology described in this study, is of course limited by the validity of that measure.

\section{Conclusions and Further Research}

The contribution of this study lies in the illumination of not just the size, but the nature and determinants of the gender differences, which have been observed in numerous studies of the MFT-B. Previous research on the determinants of MFT-B scores estimated coefficients at the mean. However, as this study demonstrates, it is both interesting and helpful to see the determinants of the MFT-B scores examined at all points of the distribution. The use of quantile regression, which examines relationships at all points on the distribution curve, would seem to substantially improve the accuracy of the assessment of learning and contribute to a better understanding of the contribution of dispositional factors, such as gender, which impact academic achievement as compared with estimates of the coefficients on sample means obtained by the use of OLS. We encourage others to replicate, critique, and improve on this methodology.

The relatively large multi-year data set used in this study has permitted an examination of differential gender performance comparisons within and between different cohorts at the same institution. Generalization of the findings regarding the size, nature, and determinants of these gender differentials will be enhanced by replications in other institutional settings and studies across different institutions.

Most importantly, study results suggest that statistically significant gender differences on the MFT-B assessment disappear after controlling for critical thinking skills. This result can be helpful in understanding differential gender performance on this widely used assessment of learning and concerns regarding gender bias. Replication and additional study of gender performance on the MFT-B is strongly encouraged.

Finally, this study suggests that men and women react differently to an offer of academic extra credit for good performance on the MFT-B. While an extra-credit offer did raise the MFT-B institutional mean, in this study only men in the top half of the MFT-B score distribution seemed to be positively impacted by the extra-credit offer, something which those considering a similar offer might wish to consider.

\section{REFERENCES}

Allen, J. S., \& Bycio, P. (1997). An evaluation of the Educational Testing Service Major Field Achievement Test in Business. Journal of Accounting Education, 15, 503-514.

Bagamery, B. D., Lasik, J. J., \& Nixon, D. R. (2005). Determinants of success on the ETS Business Major Field exam for students in an undergraduate multisite regional university business program. Journal of Education for Business, 81, 55-63.
Barboza, G. A., \& Pesek, J. (2012). Linking course-embedded assessment measures and performance on the Educational Testing Service Major Field Test in Business. Journal of Education for Business, 87, 102-111.

Bean, D. F., \& Bernardi, R. A. (2002). Performance on the major field test in business: The explanatory power of SAT scores and gender. Journal of Private Enterprise, 17/18, 172-178.

Bielinska-Kwapisz, A., \& Brown, F. W. (2011, March). The impact of intellectual diversity on business education. Paper presented on the Global Business Development Institute's 14th International Conference for Business and Economics, Las Vegas, NV.

Bielinska-Kwapisz, A., Brown, F. W., \& Semenik, R. J. (2012a). Is higher better? Determinants and comparisons of performance on the Major Field Test-Business. Journal of Education for Business, 87, 159-169.

Bielinska-Kwapisz, A., Brown, F. W., \& Semenik, R. J. (2012b). Interpreting standardized assessment test scores and setting performance goals in the context of student characteristics: The case of the major field test in business. Journal of Education for Business, 87, 7-13.

Black, H. T., \& Duhon, D. L. (2003). Evaluating and improving student achievement in business programs: The effective use of standardized assessment tests. Journal of Education for Business, 79, 90-98.

Brookfield, S. D. (1987). Developing critical thinkers: Challenging adults to explore alternative ways of thinking and acting. San Francisco, CA: Jossey-Bass.

Bycio, P., \& Allen, J. S. (2007). Factors associated with performance on the educational testing service (ETS) Major Field Achievement Test in Business (MFT-B). Journal of Education for Business, 82, 196-201.

Contreras, S., Badua, F, Chen, J, S., \& Adrian, M. (2011). Documenting and explaining Major Field Test results among undergraduate students. Journal of Education for Business, 86, 64-70.

Educational Testing Service. (2009). A guided tour of the Major Field Tests. Retrieved from http://www.ets.org/Media/Tests/MFT-B/demo/ MFT-Bdemoindex.html

Educational Testing Service. (2010). Test description. Retrieved from http:// www.ets.org/Media/Tests/MFT/pdf/mft_testdesc_business_4cmf.pdf

Educational Testing Service. (2011). Comparative data. Retrieved from http://www.ets.org/s/mft/pdf/2011/business4gmf.pdf

Eide, E., \& Showalter, M. H. (1998). The effect of school quality on student performance: A quantile regression approach. Economics Letters, 58, 345-350.

Escudero, W. S., Giovagnoli, P. I., \& Porto, A. (2009). The effects of individual characteristics on the distribution of college performance. Económica, $L V$, 99-130.

Facione, P. A. (1990). California Critical Thinking Skills Test: College level. Millbrae, CA: California Academic Press.

Facione, P. A., \& Facione, N. C. (1994). The California Critical Thinking Skills Test. Test manual. Millbrae, CA: California Academic Press.

Facione, P. A., Giancarlo, C. A., Facione, N. C., \& Gainen, J. (1995). The disposition toward critical thinking. The Journal of General Education, $44,1-25$.

Hallock, K. F., Madalozzo, R., \& Reck, C. G. (2008). CEO pay-forperformance heterogeneity: Examples using quantile regression. The Financial Review, 45, 1-19.

Insight Assessment. (2011). The international measurement of critical thinking. Retrieved from http://www.insightassessment.com/ Scales\%20CCTST.html

Jacobs, S. S. (1995). Technical characteristics and some correlates of the California Critical Thinking Skills Test, forms a and b. Research in Higher Education, 36, 89-108.

Jenkins, E. K. (1998). The significant role of critical thinking in predicting auditing students' performance. Journal of Education for Business, 73, 274-279.

King, P. M., \& Kitchener, K. S. (1994). Developing reflective judgment: Understanding and promoting intellectual growth and critical thinking in adolescents and adults. San Francisco, CA: Jossey-Bass.

Koenig, K. A., Frey, M. C., \& Detterman, D. K. (2008). ACT and general cognitive ability. Intelligence, 36, 153-160. 
Koenker, R., \& Bassett, G. Jr. (1978). Regression quantile. Econometrica, $46,33-50$

Koenker, R., \& Hallock, K. F. (2001). Quantile regression. Journal of Economic Perspectives, 15, 143-156.

Kurfiss, J. G. (1988). Critical thinking: Theory, research, practice, and possibilities (Report no. 2). Washington, DC: Association for the Study of Higher Education (ASHE-ERIC Document Reproduction Service).

Levin, J. (2001). For whom the reductions count: A quantile regression analysis of class size and peer effects on scholastic achievement. Empirical Economics, 26, 221-246.

Martell, K. (2007). Assessing student learning: Are business schools making the grade? Journal of Education for Business, 82, 189-195.

Mason, P. M., Coleman, B. J., Steagall, J. W., Gallo, A. A., \& Fabritius, M. M. (2011). The use of the ETS Major Field Test for assurance of business content learning: Assurance of waste? Journal of Education for Business, 86, 71-77.

Mirchandani, D., Lynch, R., \& Hamilton, D. (2001). Using the ETS Major Field Test in Business: Implications for assessment. Journal of Education for Business, 77, 51-55.

Parmenter, D. A. (2007). Drawbacks to the utilization of the ETS Major Field Test in Business for outcomes assessment and accreditation. Proceedings of the Academy of Educational Leadership, 12, 45-55.

Prieto-Rodriguez, J., Barros, C., \& Vieira, J. (2008). What a quantile approach can tell us about returns to education in Europe. Education Economics, 16, 391-410.
Roberts, T. G., \& Dyer, J. E. (2005). The relationship of self-efficacy, motivation, and critical thinking disposition to achievement and attitudes when an illustrated web lecture is used in an online learning environment. Journal of Agricultural Education, 46(3), 12-23.

Robinson, J. P., \& Lubienski, S. T. (2011). The development of gender achievement gaps in mathematics and reading during elementary and middle school: Examining direct cognitive assessments and teacher ratings. American Educational Research Journal, 48, 268-302.

Siebert, J, W., Litzenberg, K. K., Gallagher, R., Wilson, C. A., Dooley, F., \& Wysocki, A. (2006). Factors associated with students' academic motivation in agricultural economics classes. American Journal of Agricultural Economics, 88, 750-762.

Stater, M. (2009). The impact of financial aid on college GPA at three flagship public institutions. American Educational Research Journal, 46, $782-815$.

Stoloff, M., \& Feeney, K. J. (2002). The Major Field Test as an assessment tool for an undergraduate psychology program. Teaching of Psychology, 29, 92-98.

Terry, N., Mills, L., Rosa, D., \& Sollosy, M. (2009). Do online students make the grade on the Business Major Field ETS exam? Academy of Educational Leadership Journal, 13, 109-118.

Zeis, C., Waronska, A., \& Fuller, R. (2009).Value-added program assessment using nationally standardized tests: Insights into internal validity issues. Journal of Academy of Business and Economics, 9, $114-128$. 